\title{
Evolution of strategies for management of the patent arterial duct
}

Keywords: Persistent ductus arteriosus; side effects; complications

Sir,

I read with interest the review by Giroud and Jacobs ${ }^{1}$ concerning the evolution of strategies for management of the persistently patent arterial duct. They emphasize that the issue of the "silent" duct is controversial, and they recommend intervention in this setting. They "explain the natural history of the persistently patent arterial duct to the parents" when obtaining informed consent. It is my opinion that, currently, it is impossible to provide appropriate information concerning the natural history of the "silent" duct so as to give the necessary information. As they discuss, there are only very few anecdotal reports of endocarditis. In two of these reports ${ }^{2,3}$ of endarteritis occurring in the setting of a "silent" duct, both patients were treated successfully with antibiotics and had no residual findings. Thus, the "devastating effects of endocarditis", information presented by Giroud and Jacobs to the parents, are also questionable. Furthermore, I believe that using the accurate terminology of "endarteritis" when discussing this issue might reduce fear of the parents, and therefore influence their decision.

It is also the case that Giroud and Jacobs are unable to provide adequate information concerning the outcome of interventional closure of the duct, as no long term studies of this procedure are yet available.

In former years, surgical ligation of the duct without concomitant division left up to one-fifth of patients with a remaining very tiny residual duct, ${ }^{4}$ a situation akin to the "silent" duct. Those residual tiny ducts have been well tolerated, and further surgery has not been attempted. To the best of my knowledge, there are no reports of endarteritis in those patients. On the other hand, persistence of

Correspondence to: Dr med. Dipl. Psych. Alex Gillor, Sachsenring 29-31, 50677 Cologne, Germany. Tel: +49 221 9232393; Fax: +49 2219232394 ; E-mail: alex.gillor@diekinderkardiologen.de

Accepted for publication 27 December 2007 a small residual shunt subsequent to implantation of a device would leave the patient at high risk for endarteritis, according to the recent recommendations for prophylaxis against endocarditis provided by the American Heart Association. In our own review of the literature, we tried to compare the risks of a "silent" duct with the risks of interventional closure. ${ }^{5}$ Due to continuous change in strategies for interventional closure of the duct, and the inhomogeneous nature of the populations treated, the comparison is problematic. It seemed to us, nonetheless, that the risks of interventional closure in childhood are higher than those for the "silent" duct left untreated. Even if there were no complications, the procedure itself is not harmless. It is invasive, causes pain, requires exposure to $\mathrm{x}$-rays and anaesthetics, and involves cost. According to my belief, and in keeping with the aphorism originating from Hippocrates "primum non nocere", or "first, do no harm", physicians advocating closure of the persistently patent arterial duct must provide indisputable proof that closure is superior to nihilism.

\section{Alex Gillor Gemeinschaftspraxis für Kinderkardiologie Köln, Germany}

\section{References}

1. Giroud JM, Jacobs JP. Evolution of strategies for management of the patent arterial duct. Cardiol Young 2007; 17 (Suppl. 2): II68-II74.

2. Balzer DT, Spray TL, McMullin D, Cottingham W, Canter CE. Endarteritis associated with a clinically silent patent ductus arteriosus. Am Heart J 1993; 125: 1192-1193.

3. Parthenakis FI, Kanakaraki MK, Vardas PE. Silent patent ductus arteriosus Endarteritis. Heart 2000; 84: 619.

4. Schmaltz AA, Reidemeister JC, Neudorf U, Doetsch N, Hentrich F. Restshunts nach chirurgischer Ductusligatur. Z Herz-, Thorax-, Gefäßchirurgie 1994; 8: 91-94.

5. Gillor A, Perrey SE, Schnegg C. Soll ein silenter persistierender Ductus arteriosus Botalli verschlossen werden? Monatsschrift Kinderheilkunde 2006; 154: 669-673. 